\title{
Persistent Airway Inflammation after Resolution of Respiratory Syncytial Virus Infection in Rats
}

\author{
GIOVANNI PIEDIMONTE, RICHARD G. HEGELE, AND ALEXANDER AUAIS \\ Departments of Pediatrics [G.P., A.A.], Medicine [G.P.], and Molecular/Cellular Pharmacology [G.P.], \\ University of Miami School of Medicine, Miami, Florida 33136, U.S.A.; and University of British \\ Columbia McDonald Research Laboratories and iCAPTURE Centre [R.G.H.], Vancouver, British \\ Columbia V6Z 1Y6, Canada
}

\section{ABSTRACT}

\begin{abstract}
Neurogenic inflammation is markedly potentiated in airways that are infected with respiratory syncytial virus (RSV). Aims of this study were to determine whether this potentiation persists after the virus is cleared, investigate the mechanism of postviral potentiation, and define whether prophylaxis with a MAb against the RSV fusion protein (palivizumab) prevents this effect. Thirty days after inoculation, no evidence of active RSV infection was found in the airway epithelium by plaque assay or immunostaining and no viral nucleic sequences were detected by PCR, yet capsaicin-induced plasma extravasation in the airways that were infected $30 \mathrm{~d}$ earlier with RSV was still significantly larger compared with pathogen-free controls. Substance P content in lung tissues and capsaicin-induced release of this peptide from sensory nerves were significantly increased at $30 \mathrm{~d}$. The administration of palivizumab $24 \mathrm{~h}$ before virus inoculation prevented the development of abnormal neurogenic inflammatory responses. Our data suggest that the airways remain abnormally
\end{abstract}

susceptible to the proinflammatory effects of sensory nerves after RSV infection is cleared, as a result of changes in sensory innervation, and that this abnormality can be prevented by passive prophylaxis against RSV. (Pediatr Res 55: 657-665, 2004)

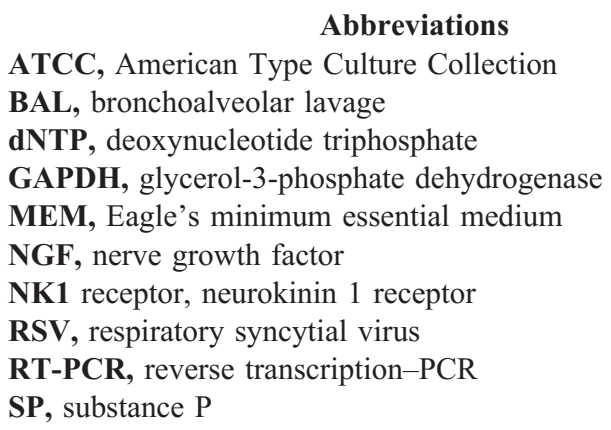

Respiratory syncytial virus (RSV) infection presents a large public health burden worldwide (1). Half of all infants become infected with RSV in the first year of life, and by $2 \mathrm{y}$ of age, most children have been infected with RSV at least once. RSV is estimated to cause up to $90 \%$ of all childhood bronchiolitis and up to $40 \%$ of all pediatric pneumonias, resulting in $>120,000$ hospitalizations annually in the United States (2). In addition, there is growing evidence that early RSV infection is an important risk factor for the development of recurrent wheezing during the first decade of life (3). Despite intense

Received March 21, 2003; accepted September 12, 2003.

Correspondence: Giovanni Piedimonte, M.D., Batchelor Children's Research Institute, Pediatric Pulmonology \& Cystic Fibrosis Center, University of Miami School of Medicine, 1580 NW 10th Avenue, Miami, FL 33136; e-mail: gpiedimo@med.miami.edu

This research was supported in part by a grant from the National Institutes of Health (NHLBI HL-61007) and by a research grant from MedImmune, Inc. to Dr. Giovanni Piedimonte.

Some of the findings reported in this article were presented at the 2001 American Thoracic Society Conference in San Francisco, CA, U.S.A., and at the 2002 American Thoracic Society Conference in Atlanta, GA, U.S.A.

DOI: 10.1203/01.PDR.0000112244.72924.26 research efforts, the mechanism by which this virus predisposes to long-term sequelae is still unclear.

In previous studies, we have shown that during an acute RSV infection the airways become abnormally susceptible to the proinflammatory effects of the neurotransmitter substance $P$ (SP) released from sensory nerves, as a result of up-regulation of the high-affinity SP [neurokinin 1 (NK1)] receptor (4). This effect can be prevented by the administration of a MAb against the RSV fusion protein (palivizumab; MedImmune, Inc., Gaithersburg, MD, U.S.A.), given either before inoculation or during the early phase of the infection (5). However, for linking the acute viral infection with the development of long-term changes, it is essential to establish that the inflammatory changes persist after the virus is cleared from the airways.

In the present study, we first analyzed lung tissues obtained from rats $5 \mathrm{~d}$ or $30 \mathrm{~d}$ after inoculation of RSV to establish whether evidence of persistent viral infection can be found after resolution of the acute phase. Then we investigated whether the increased neurogenic plasma extravasation ob- 
served in RSV-infected airways persists $30 \mathrm{~d}$ after inoculation of the virus, when the acute phase of the infection in our model is resolved. In addition, we studied whether prophylaxis with palivizumab prevents the development of postviral abnormalities. Finally, we compared the expression of the SP (NK1) receptor gene and SP concentration and release in the lungs of rats that were acutely infected with RSV and rats that were previously infected with the virus to understand the mechanism of the persistent changes in neurogenic-mediated airway inflammation caused by RSV.

\section{METHODS}

Animals. We used pathogen-free adult rat strain Fischer 344 (F-344) from Charles River Breeding Laboratories (Raleigh, NC, U.S.A.). All rats were $12 \mathrm{wk}$ old at the beginning of the experiments. Because previous studies have shown a profound effect of respiratory infections on neurogenic control and inflammatory responses in the respiratory tract $(6,7)$, all animals that were used in this study were maintained under strict barrier conditions to prevent any microbial contamination. Groups of two rats were housed in polycarbonate cages isolated by polyester filter covers. These cages were placed on racks that provided positive individual ventilation with class 100 air to each cage at the rate of approximately one cage change of air per minute (Maxi-Miser; Thoren Caging System, Hazleton, PA, U.S.A.) $(4,5,8)$. We used separate rooms for housing infected and pathogen-free rats, both serviced by specifically trained husbandry technicians. All manipulations were conducted inside class 100 laminar flow hoods. Bedding, water, and food were autoclaved before use and unpacked only under laminar flow. Cages and water bottles were run through a tunnel washer after every use and disinfected with both chemicals and heat. The Division of Veterinary Resources of the University of Miami School of Medicine approved all experimental procedures followed in this study.

Preparation and inoculation of RSV. RSV suspensions were prepared as described previously $(4,5,8)$. In brief, HEp-2 cells from the American Type Culture Collection (ATCC; Rockville, MD, U.S.A.) were grown in Eagle's minimum essential medium (MEM; GIBCO BRL, Grand Island, NY, U.S.A.) supplemented with $10 \%$ fetal bovine serum (GIBCO BRL). Confluent monolayers of HEp-2 cells were infected with 0.1 plaque-forming units of human RSV strain $\mathrm{A}_{\text {Long }}$ (ATCC), and the infection was allowed to proceed at $37^{\circ} \mathrm{C}$ in $5 \% \mathrm{CO}_{2}$ atmosphere until $>75 \%$ of the cells exhibited a cytopathic effect. Cell debris was removed by centrifugation at $9500 \times g$ for $20 \mathrm{~min}$ in a centrifuge refrigerated at $4^{\circ} \mathrm{C}$. Aliquots of the virus stock were snap-frozen in liquid nitrogen and stored at $-80^{\circ} \mathrm{C}$. Before inoculation, the virus stock was titrated and diluted as needed to obtain a final titer of $5 \times 10^{4} 50 \%$ tissue culture infective dose in $0.1 \mathrm{~mL}$. Supernatants and cell lysates from virus-free flasks of HEp-2 cells in MEM were harvested, centrifuged, and aliquotted following the same protocol to obtain the virus-free medium used as a negative control. Rats under pentobarbital sodium anesthesia $(50 \mathrm{mg} / \mathrm{kg}$ i.p.) were inoculated with RSV suspension or virus-free medium as described previously. A $50-\mu \mathrm{L}$ volume of the virus suspension described above was gently deposited in each nostril using a pipette. Control rats were dosed with the same volume of virus-free medium.

RSV titration. Viral titration from lung tissues was performed at 5 and $30 \mathrm{~d}$ after inoculation of RSV suspension from the same stock aliquot. The lungs were homogenized in $10 \mathrm{~mL}$ of MEM containing 5\% fetal bovine serum, and the supernatant obtained by centrifugation at $1500 \times g$ for $15 \mathrm{~min}$ at $4^{\circ} \mathrm{C}$ was stored at $-70^{\circ} \mathrm{C}$. Titration was carried out by standard plaque assay in HEp-2 cells, and results were expressed in plaque-forming units (pfu) $/ \mathrm{mL}$. Titration of the viral stock used for inoculation yielded $3.2 \times 10^{7} \mathrm{pfu} / \mathrm{mL}$.

RSV antigens detection. Immunoperoxidase staining for RSV detection and hematoxylin/eosin staining for histopathologic analysis were performed on formalin-fixed $3 \mu \mathrm{m}$-thick lung sections. As described previously $(4,5,8)$, sections for RSV detection were incubated with a 1:400 dilution of a pool of MAb composed of four clones specific for the matrix (M2) protein, phosphoprotein $(\mathrm{P})$, fusion $(\mathrm{F})$ protein, and nuclear $(\mathrm{N})$ protein of human RSV (Vector Laboratories, Burlingame, CA, U.S.A.). This technique has been shown to maximize the sensitivity of RSV detection (9). Localization of the primary antibodies was delineated with the streptavidin-biotin peroxidase complex method using an immunostaining kit (DAKO) and developed with the 3,3'-diaminobenzidine tetrahydrochloride chromogen. With this technique, cells expressing target antigens are stained with a dark-brown precipitate lining the cell membrane and cytoplasm. All slides were coded and were interpreted by a pathologist, who did not know whether the section corresponded to an RSV-inoculated or to a mediuminoculated animal.

Detection of RSV nucleic acid. The presence of RSV RNA in lung tissues was detected by reverse transcription-PCR (RT-PCR) in frozen lung tissue specimens shipped in dry ice to the University of British Columbia (Vancouver, BC, Canada; R.G.H.), based on previously published work (10). Total RNA was extracted from homogenates of the upper and lower lobes of the right lung using RNEasy Midi-Kits (Qiagen $\mathrm{GmbH}$, Hilden, Germany) according to the manufacturer's instructions. Positive controls consisted of RNA extracted from human RSV strain $A_{\text {Long }}$ specimens (ATCC), whereas RNA extracted from cultures of uninfected HEp-2 cells served as a negative control. RNA samples $(50 \pm 2 \mu \mathrm{g}$ of total RNA; median \pm SEM $)$ underwent reverse transcription in duplicate at $37^{\circ} \mathrm{C}$ for $1 \mathrm{~h}$ in a $50-\mu \mathrm{L}$ reaction mixture consisting of $10 \mathrm{mM}$ Tris- $\mathrm{HCl}(\mathrm{pH} 8.3)$, $50 \mathrm{mM} \mathrm{KCl}, 5 \mathrm{mM} \mathrm{MgCl}{ }_{2}, 50 \mu \mathrm{M}$ each of deoxynucleotide triphosphates (dNTPs), 50 units of RNase inhibitor (Pharmacia, Mississauga, Ontario, Canada), $5 \mu \mathrm{g}$ of random hexamers (Pharmacia), and 250 units of cloned Moloney murine leukemia virus reverse transcriptase (GIBCO BRL). Heating the reaction mixture at $95^{\circ} \mathrm{C}$ for $5 \mathrm{~min}$ inactivated reverse transcriptase activity. Five microliters of the cDNA product from the reverse transcription reaction was used in a $50-\mu \mathrm{L}$ PCR reaction mixture that consisted of $10 \mathrm{mM}$ Tris- $\mathrm{HCl}$ ( $\mathrm{pH} 8.3$ ), $50 \mathrm{mM} \mathrm{KCl}, 2.5 \mathrm{mM} \mathrm{MgCl}{ }_{2}, 50 \mu \mathrm{M}$ each of dNTPs, 1.5 units of Taq DNA polymerase (GIBCO BRL), and $50 \mathrm{pmol}$ each of primers flanking a 410-nucleotide sequence of the human RSV nucleocapsid gene (antisense 
5'-GCGAtGtCTAGgtTA-GGAAGAA-3', sense 5'GCTTCCTTGGGTAGT-AAGCCT-3'; University of Calgary, Calgary, AB, Canada). These primers were designed on the basis of results of a Genbank search that showed a lack of homology between the sequences of these oligonucleotides to published sequences from other microorganisms or primates. Samples underwent denaturation at $94^{\circ} \mathrm{C}$ for 4 min, followed by 35 cycles of amplification in a thermal Robocycler-40 (Stratagene, La Jolla, CA, U.S.A.); each cycle consisted of denaturation at $94^{\circ} \mathrm{C}$ for $1 \mathrm{~min}$, annealing at $55^{\circ} \mathrm{C}$ for $1 \mathrm{~min}$, and extension at $72^{\circ} \mathrm{C}$ for $1.5 \mathrm{~min}(8 \mathrm{~min}$ for last cycle). After amplification, the PCR products underwent electrophoresis on ethidium bromide-stained $1.5 \%$ agarose gels and were visualized under UV light.

After Southern transfer onto Hybond-N nylon membranes (Amersham, Arlington Heights, IL, U.S.A.) and cross-linking under UV light, PCR products were hybridized with an oligonucleotide probe (5'-TAGCTCCAGAATAGTAAGCCT-3') that was end-labeled with $\left(\gamma_{-}{ }^{32} \mathrm{P}\right)$ ATP using the T4 polynucleotide kinase reaction (GIBCO BRL) following the manufacturer's instructions. Hybridization was carried out in a hybridization oven (Hybaid, Colchester, UK) at $65^{\circ} \mathrm{C}$ for $18 \mathrm{~h}$ in a solution consisting of $6 \times \mathrm{SSC}[0.9 \mathrm{M} \mathrm{NaCl}, 0.09 \mathrm{M}$ sodium citrate $[\mathrm{pH} 7.0)], 5 \times$ Denhardt's solution $(0.1 \%$ Ficoll $400,0.1 \%$ BSA fraction $\mathrm{V}, 0.1 \%$ polyvinylpyrrolidone), $0.5 \%$ SDS, and $100 \mu \mathrm{g} / \mathrm{mL}$ fragmented salmon sperm DNA. After hybridization, membranes were washed in $6 \times \mathrm{SSC}$ three times for $5 \mathrm{~min}$ at room temperature and $30 \mathrm{~min}$ at $65^{\circ} \mathrm{C}$ and exposed to Kodak x-ray film (Eastman Kodak, Rochester, NY, U.S.A.) for up to $72 \mathrm{~h}$.

For quality assurance, PCR experiments were performed in duplicate to achieve concordance of results. For ensuring that the RNA nucleic acid extraction procedure yielded specimens that did not contain PCR inhibitors, specimens underwent RT-PCR for a 445-nucleotide sequence of the constitutively expressed "housekeeping" gene glycerol-3-phosphate dehydrogenase (GAPDH), using flanking oligonucleotide primers (antisense 5'-CCCATCACCATCTTCCAG-3', sense 5'ATGACCTTGCCCACAGCC-3') and internal probe (5'TCACCACCATGGAGAAGG-3'). A PCR result was considered positive when an unequivocal band of predicted size was seen on autoradiographs from both replicates of each sample in the presence of predicted results for known positive and negative cell culture control specimens.

Albumin extravasation. Rats were re-anesthetized with pentobarbital sodium $(50 \mathrm{mg} / \mathrm{kg}$ i.p.). Evans blue dye $(30 \mathrm{mg} / \mathrm{kg}$ i.v. over $5 \mathrm{~s}$ ) was injected into the femoral vein to measure the extravasation of albumin from airway blood vessels (11). Immediately after the injection of the tracer, sensory nerves in the respiratory tract were stimulated with a 2 -min i.v. infusion of $75 \mu \mathrm{g} / \mathrm{kg}$ capsaicin (8-methyl-N-vanillyl-6-nonenamide; Sigma Chemical Co., St. Louis, MO, U.S.A.) dissolved in a vehicle with a final concentration of $0.75 \%$ ethanol, $0.375 \%$ Tween 80 , and $0.85 \% \mathrm{NaCl}$ in aqueous solution (12). In a separate experiment, plasma extravasation was elicited with the injection of exogenous SP $(1 \mu \mathrm{g} / \mathrm{kg}$ over $20 \mathrm{~s}$; Sigma Chemical Co.). These threshold concentrations of capsaicin and SP have little effect on airway vascular permeability in pathogen-free rats, whereas they cause large plasma extravasation during the acute phase of RSV infection, i.e. $5 \mathrm{~d}$ after inoculation of the virus (4). All drugs used for these experiments were delivered in a volume of $1 \mathrm{~mL} / \mathrm{kg}$ body weight.

Five minutes after the injection of the tracer, the chest was opened, a cannula was inserted into the ascending aorta through the left ventricle, and the circulation was perfused for 2 min with PBS using a syringe pump set at the rate of 50 $\mathrm{mL} / \mathrm{min}$. The extrapulmonary airways (from the first tracheal ring to the end of the main stem bronchi) and the left lung were dissected and prepared for Evans blue extraction. The specimens free of connective tissue and opened along the ventral midline were blotted with bibulous paper, weighed, and incubated in $1 \mathrm{~mL}$ of formamide (Sigma Chemical Co.) at $50^{\circ} \mathrm{C}$ for $18 \mathrm{~h}$ to extract the extravasated Evans blue dye.

The extravasation of Evans blue-labeled albumin from the tracheobronchial microcirculation was quantified by measuring the optical density of the formamide extracts at 620 -nm wavelength. The quantity of Evans blue dye extravasated in the airway tissues, expressed in nanogram per milligram of wet tissue weight, was interpolated from a standard curve of Evans blue concentrations $(0.5-10 \mu \mathrm{g} / \mathrm{mL})$.

Bronchoalveolar lavage. We performed bronchoalveolar lavage (BAL) by infusing $28 \mathrm{~mL} / \mathrm{kg}$ PBS via a tracheal cannula under pentobarbital anesthesia. The lavage fluid was instilled and withdrawn three times, and the recovery efficiency ranged between 75 and $85 \%$ for each of the animals.

$\boldsymbol{S P}$ (NK1) receptor $\boldsymbol{m R N A}$ expression. $\mathrm{mRNA}$ levels in lung tissues were measured by semiquantitative RT-PCR based on previously published work $(4,8)$. Total cellular RNA was extracted from lung tissue homogenates in $1 \mathrm{~mL}$ of TriReagent solution (Molecular Research Center, Cincinnati, OH, U.S.A.). For the synthesis of cDNA, $1 \mu \mathrm{g}$ of RNA from each sample was resuspended in a $20-\mu \mathrm{L}$ final volume of reaction buffer containing $10 \mathrm{mM}$ Tris- $\mathrm{HCl}(\mathrm{pH} 8.3), 50 \mathrm{mM} \mathrm{KCl}, 5$ $\mathrm{mM} \mathrm{MgCl} 2,1 \mathrm{mM}$ of each dNTP, $1 \mathrm{U} / \mu \mathrm{L}$ RNAse inhibitor, and $2.5 \mu \mathrm{M}$ Oligo-d $(\mathrm{T})_{16}$ primer. Moloney murine leukemia virus reverse transcriptase $(2.5 \mathrm{U} / \mu \mathrm{L}$; Perkin-Elmer, Foster City, CA, U.S.A.) was added to each tube, and the reaction was allowed to proceed for $10 \mathrm{~min}$ at room temperature, then for 30 $\min$ at $42^{\circ} \mathrm{C}$. Five-microliter aliquots of the synthesized cDNA (corresponding to $100 \mathrm{ng}$ of RNA) were added to a $45-\mu \mathrm{L}$ PCR mixture containing $5 \mu \mathrm{L}$ of $10 \times$ PCR buffer, $2 \mu \mathrm{L}$ of deoxynucleotides $\left(0.4 \mathrm{mM}\right.$ each), $1 \mu \mathrm{L}$ of $3^{\prime}$ and $5^{\prime}$ specific primers $(0.2 \mu \mathrm{M}$ each), and $0.25 \mu \mathrm{L}$ of AmpliTaq Gold DNA polymerase $(5 \mathrm{U} / \mu \mathrm{L}$; Perkin-Elmer).

PCR amplification of the rat SP (NK1) receptor was performed using the following primer sequences: sense 5'CATCAACCCAGATCTCTACC-3' targeting bases 13711391 and antisense 5'-GCTGGAGCTTTCTGTCATGGA-3' targeting bases $1735-1755$. The housekeeping gene GAPDH was amplified simultaneously as an internal standard using the following primer sequences: sense 5'-TGAAGGTCGGTGTCAACGGATTTGGC-3' targeting bases 35-60 and antisense 5'-CATGTAGGCCATGAGGTCCACCAC-3' targeting bases 994-1017. As a positive control, we used the full-length rat SP (NK1) receptor cDNA (13). Amplification was initiated with 10 -min denaturation at $94^{\circ} \mathrm{C}$ for 1 cycle followed by 35 cycles 
at $94^{\circ} \mathrm{C}$ for $45 \mathrm{~s}, 55^{\circ} \mathrm{C}$ for $45 \mathrm{~s}$, and $72^{\circ} \mathrm{C}$ for $60 \mathrm{~s}$ using a thermal cycler (GeneAmp PCR System 9600, Perkin-Elmer). After the last cycle of amplification, the samples were incubated for $10 \mathrm{~min}$ at $72^{\circ} \mathrm{C}$. RNA concentrations and PCR cycler were titrated to establish standard curves to document linearity and to permit semiquantitative analysis of signal strength. Amplified PCR products were separated by electrophoresis through $2 \%$ agarose gel at $45 \mathrm{~V}$ for $120 \mathrm{~min}$. The cDNA bands were visualized by UV illumination after staining the gels with $0.5 \mathrm{mg} / \mathrm{mL}$ ethidium bromide dissolved in Tris Borate-EDTA buffer [89 mM Tris, $89 \mathrm{mM}$ boric acid, $2.5 \mathrm{mM}$ EDTA (pH 8.2)]. The gels were photographed, and the films were scanned and analyzed with a computerized densitometer.

SP immunoassay. SP concentration in lung tissues homogenates and BAL fluid samples was measured using a commercial kit (Cayman Chemicals, Ann Arbor, MI, U.S.A.). In brief, $\sim 100 \mathrm{mg}$ of tissue from each lung sample was homogenized on ice in $1 \mathrm{~mL}$ of lysis buffer containing $0.1 \%$ trifluoroacetic acid, $10 \mu \mathrm{M}$ phosphoramidon, $10 \mu \mathrm{M}$ captopril, $2 \mu \mathrm{M}$ aprotinin, and $1 \mu \mathrm{M}$ pepstatin. After centrifugation at $9000 \times g$ for 30 min at $4{ }^{\circ} \mathrm{C}$, the samples were diluted in $4 \%$ acetic acid and SP was purified by solid-phase extraction through octadecyl C18 columns (Amprep; Amersham Life Science, Little Chalfont, England). The samples were evaporated to dryness and reconstituted with buffer for analysis.

This enzyme-linked immunoassay is based on the competition between unlabeled SP and a fixed quantity of SPacetylcholinesterase conjugate for a limited number of binding sites on an SP-specific antiserum. The intensity of the color change generated by the acetylcholinesterase read at 405-nm wavelength is inversely proportional to the concentration of free SP in the sample. SP standards and test samples were assayed in duplicate, and each sample was measured at two dilutions $(50 \mu \mathrm{L}$ of sample/well and $25 \mu \mathrm{L}$ of sample $+25 \mu \mathrm{L}$ of additional buffer/well). SP concentration measured from lung samples was normalized to wet weight. With the use of this assay, SP can be identified with $100 \%$ specificity and with a lower detection limit of $17.2 \mathrm{pg} / \mathrm{mL}$.

Experimental protocols. For exploring the time course of RSV infection in the respiratory tract of F-344 rats, groups of rats that were inoculated with either RSV or virus-free medium were killed 5 or $30 \mathrm{~d}$ after inoculation and the lungs were processed for virus titration by plaque assay, immunohistochemical identification of RSV antigens, and histopathologic analysis. We also confirmed by RT-PCR the absence of RSV nucleic acid in the lungs of rats that were killed $30 \mathrm{~d}$ after RSV inoculation ( $n=5$ rats).

For determining whether the increased neurogenic inflammatory responses persisted after resolution of the acute viral infection, rats were killed $30 \mathrm{~d}$ after inoculation, with RSV ( $n$ $=11$ rats) or with virus-free medium ( $n=12$ rats). Capsaicin was injected into five of the RSV-infected rats and six of the pathogen-free rats to stimulate sensory nerves in the airway mucosa (12). The other RSV-infected and pathogen-free rats received an injection of the vehicle used to dissolve the capsaicin. For determining whether the mechanism of post-RSV neurogenic inflammation was operating at a presynaptic or at a postsynaptic level, a group of RSV-infected rats and a group of pathogen-free controls ( $n=5$ rats each) received an i.v. injection of exogenous SP $30 \mathrm{~d}$ after inoculation.

For assessing whether a MAb specific for the viral $\mathrm{F}$ protein is protective against post-RSV neurogenic inflammation, groups of rats were treated $24 \mathrm{~h}$ before the inoculation of RSV with a s.c. injection of palivizumab (MedImmune; $15 \mathrm{mg} / \mathrm{kg}$ in $0.9 \% \mathrm{NaCl} ; n=6$ rats $)$ or its vehicle $(0.9 \% \mathrm{NaCl} ; 1 \mathrm{~mL} / \mathrm{kg} ; n$ $=5$ rats). A control group of three rats was injected with vehicle $24 \mathrm{~h}$ before intranasal administration of virus-free medium. A group of five rats that were treated with palivizumab $5 \mathrm{~d}$ after inoculation was compared with three control rats that received an injection $5 \mathrm{~d}$ postinoculation with the same volume of vehicle to assess the therapeutic effect of the MAb during established infection. The dose of palivizumab used in these studies corresponds to the dose currently used in routine clinical practice on the basis of previous studies conducted in animal models $(14,15)$.

To determine whether the up-regulation of the NK1 receptor gene expression demonstrated during RSV infection $(4,8)$ persists after resolution of the acute infection, we compared the levels of mRNA extracted from the right lung of RSV-infected and pathogen-free rats killed $30 \mathrm{~d}$ after inoculation $(n=5-6$ per group).

For determining whether RSV infection causes acute and/or chronic changes in the expression of SP in lung tissues, SP concentration was measured in the lungs from rats 5 and $30 \mathrm{~d}$ after inoculation with RSV or virus-free medium using a highly sensitive and specific immunoassay. In addition, SP concentration in BAL fluid with or without stimulation of sensory nerves with capsaicin was measured in rats that were inoculated with RSV 30 d before.

Statistical analysis. Data are expressed as the mean \pm SEM. The effects of RSV on mean values of Evans blue extravasation and SP concentration were analyzed by two-factor ANOVA (16). Multiple comparisons between means were performed with the Fisher protected least significant difference test (17). Data obtained by densitometry analysis of RT-PCR products were compared with the unpaired $t$ test. Statistical analysis was performed using the software StatView version 5.0.1 (SAS Institute, Cary, NC, U.S.A.). Differences that had a $p<0.05$ were considered significant.

\section{RESULTS}

$\boldsymbol{R S} \boldsymbol{V}$ infection. Titration by plaque assay of RSV recovered from the lungs of rats that were inoculated $5 \mathrm{~d}$ earlier revealed the presence of replicating virus in each animal, with an average titer of $3 \times 10^{2} \mathrm{pfu} / \mathrm{mL}$ (Table 1). Titration of the viral stock used for inoculation yielded $3.2 \times 10^{7} \mathrm{pfu} / \mathrm{mL}$. No evidence of replicating virus was found in the lungs of any of the rats that were killed $30 \mathrm{~d}$ after the inoculation of RSV. Immunoperoxidase staining with specific MAb performed on lung sections from F-344 rats that were killed $5 \mathrm{~d}$ after the inoculation of RSV revealed the presence of RSV antigens on the membrane and in the cytoplasm of bronchiolar epithelial cells. No virus was detected in the bronchioles of rats that were killed $30 \mathrm{~d}$ after the inoculation of RSV. Also, no virus was detected in the airways of rats 5 and $30 \mathrm{~d}$ after administration 
Table 1. RSV titer in lung tissues

\begin{tabular}{ccc}
\hline Sample no. & $\begin{array}{c}\text { RSV @ } 5 \mathrm{~d} \\
(\mathrm{pfu} / \mathrm{mL})\end{array}$ & $\begin{array}{c}\text { RSV @ 30 d } \\
(\mathrm{pfu} / \mathrm{mL})\end{array}$ \\
\hline 1 & $3.0 \times 10^{2}$ & \\
2 & $2.5 \times 10^{2}$ & \\
3 & $3.3 \times 10^{2}$ & \\
4 & $2.8 \times 10^{2}$ & \\
5 & $3.5 \times 10^{2}$ & 0 \\
6 & & 0 \\
7 & & 0 \\
8 & & 0 \\
9 & & 0 \\
10 & & 0 \\
\hline
\end{tabular}

of virus-free medium. RT-PCR amplification did not detect RSV genomic sequences in the lung tissues of any of the five animals tested.

The histopathologic changes caused by the acute RSV infection consisted predominantly of lymphomononuclear cellular infiltration in the interstitium and peribronchial areas, with only sparse polymorphonuclear leukocytes (Fig. 1). No inflammatory cells were present after $30 \mathrm{~d}$ in the lung interstitium of the RSV-inoculated or control rats.

Neurogenic inflammation. After injection of the vehicle of capsaicin (Fig. $2 A$, left columns), the extravasation of Evans blue-labeled albumin in rats that were previously infected with RSV was not significantly different from controls that were kept pathogen-free, both in the extrapulmonary airways $(p>$ $0.05)$ and in the intrapulmonary airways $(p>0.05)$.

After pharmacologic stimulation of sensory nerves with capsaicin, Evans blue extravasation in the extrapulmonary airways increased significantly $(p<0.001 ;$ Fig. $2 A$, top, center columns) and in rats that were previously infected with RSV was approximately twice that measured in pathogen-free controls that received an injection of the same dose of capsaicin $(p$ $<0.001)$. In contrast, capsaicin had no significant effect on vascular permeability in the intrapulmonary airways (Fig. $2 \mathrm{~A}$, bottom, center columns) of either previously infected rats $(p>$ $0.05)$ or pathogen-free rats $(p>0.05)$.

The intravascular injection of exogenous SP caused a small, nonsignificant increase of Evans blue extravasation in the extrapulmonary airways of previously infected rats compared with pathogen-free controls $(p>0.05)$, and no increase was measured in the intrapulmonary airways as well (Fig. $2 A$, right columns).

Capsaicin-induced Evans blue extravasation measured in the extrapulmonary airways $30 \mathrm{~d}$ after the infection was inhibited by pretreatment with palivizumab $24 \mathrm{~h}$ before inoculation $(p<$ 0.001; Fig. 2B). Treatment with palivizumab $5 \mathrm{~d}$ after RSV inoculation did not have any effect on neurogenic plasma extravasation measured $30 \mathrm{~d}$ after inoculation $(97.7 \pm 7.9$ versus $104.3 \pm 14.2 ; p>0.05)$. Average body weight measured at the end of the experiment, i.e. $30 \mathrm{~d}$ after the inoculation, was still significantly lower $(-9 \%)$ after RSV infection $(270 \pm 5 \mathrm{~g})$ than in pathogen-free controls $(297 \pm 1 \mathrm{~g} ; p<$ $0.05)$, but this difference was smaller $(-4 \%)$ for rats that were pretreated with palivizumab before the RSV infection (285 \pm $7 \mathrm{~g} ; p>0.05)$.

$S P / S P$ receptor expression. Semiquantitative RT-PCR analysis of lung tissues from rats that were inoculated with RSV did not show significant changes in SP (NK1) receptor mRNA expression after resolution of the RSV infection (Fig. 3). After normalization of the densitometry measurements to the internal standard encoding the housekeeping gene GAPDH, the level of

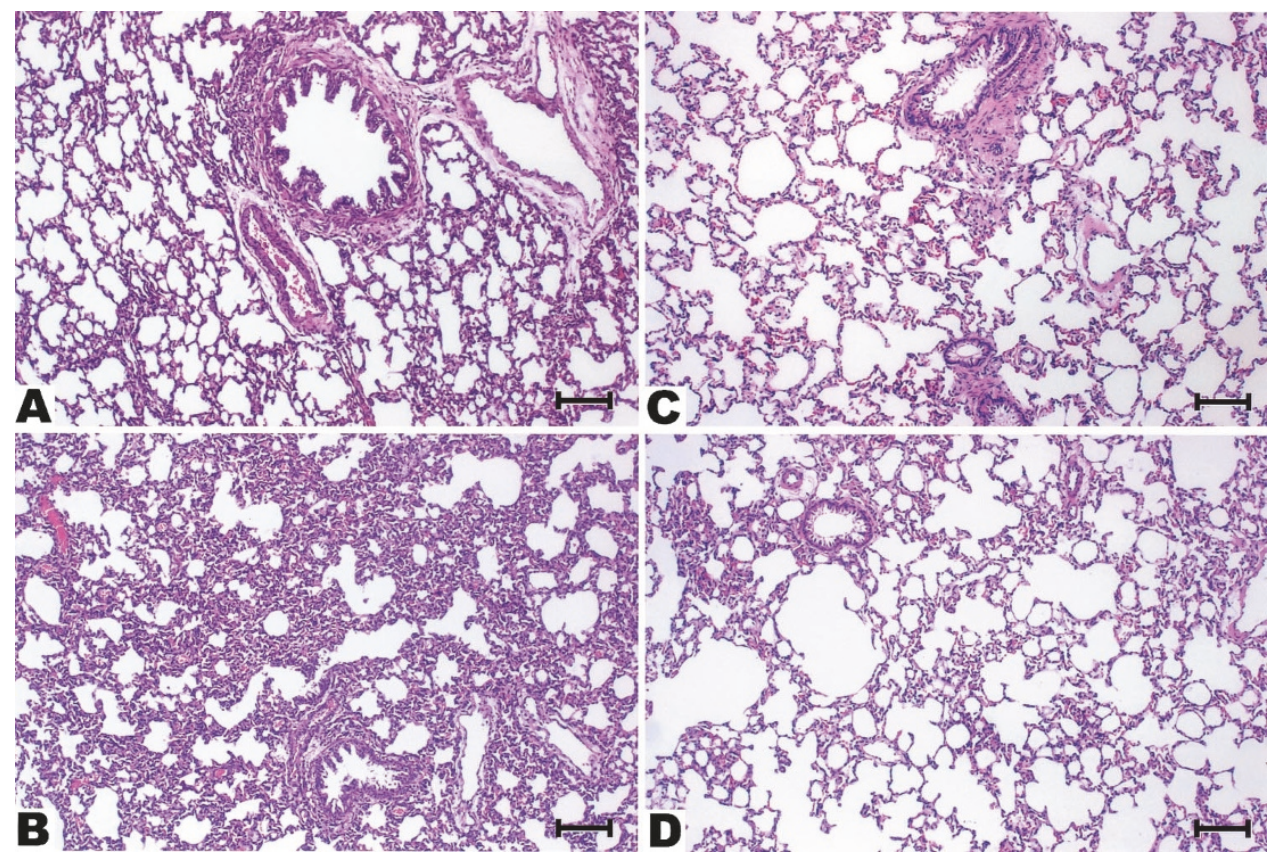

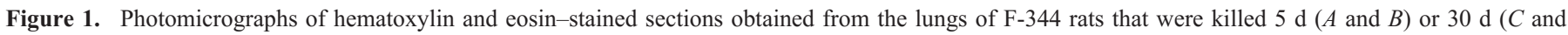

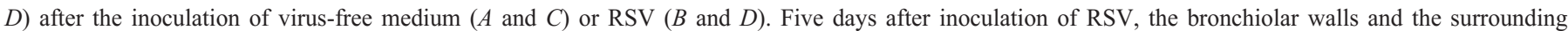

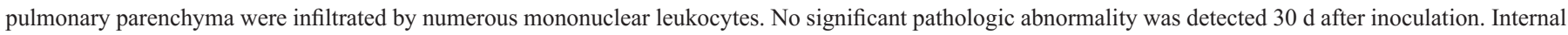
scale $=25 \mu \mathrm{m}$. 


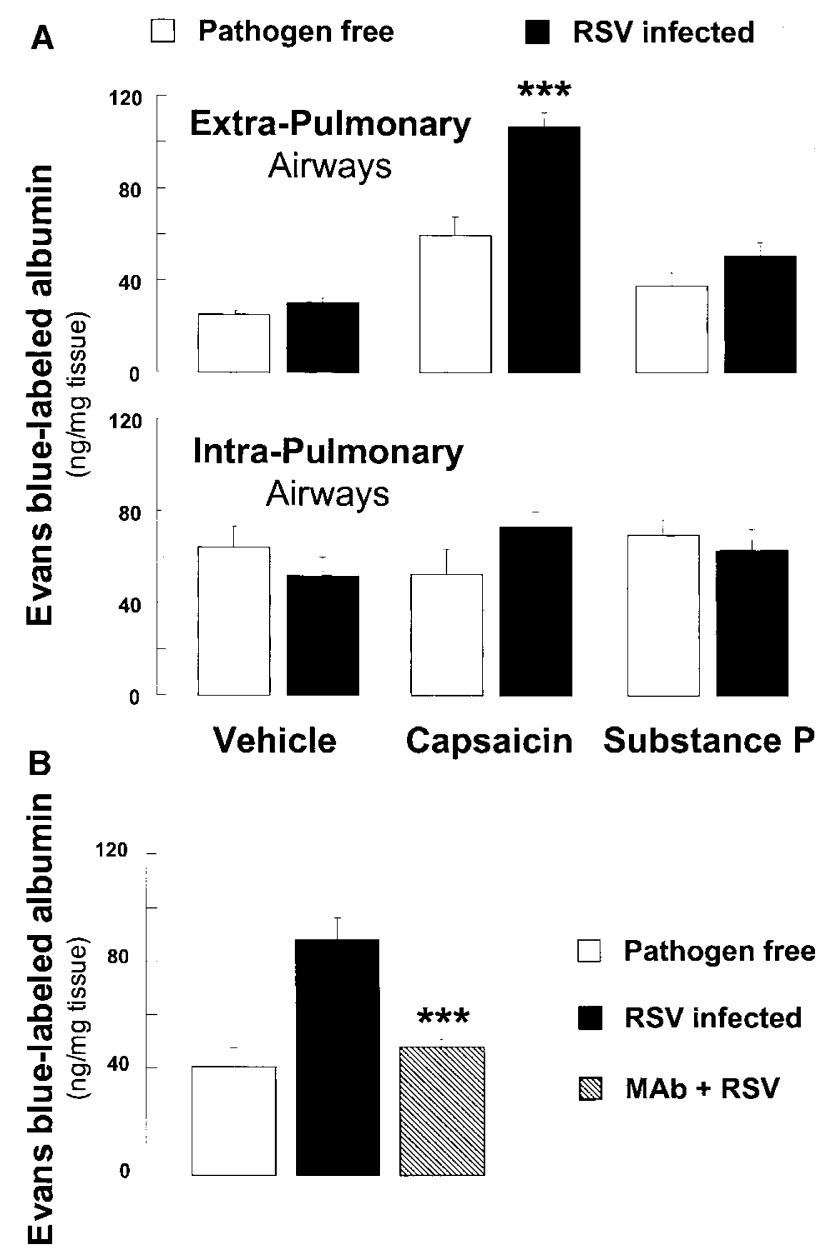

Figure 2. (A) Potentiation of airway neurogenic inflammation $30 \mathrm{~d}$ after the administration of RSV or virus-free medium measured in the extrapulmonary and intrapulmonary airways of F-344 rats. Increase in vascular permeability elicited in the extrapulmonary airways by capsaicin was still significantly larger $30 \mathrm{~d}$ post-RSV infection. Effect of exogenous SP on airway vascular permeability after RSV infection was similar to pathogen-free controls; *** $p$ $<0.001$, significantly different from pathogen-free controls. $(B)$ Palivizumab (MAb) injected $24 \mathrm{~h}$ before the inoculation of RSV inhibited capsaicin-induced Evans blue extravasation in the extrapulmonary airways measured $30 \mathrm{~d}$ postinoculation; $* * * p<0.001$, significantly different from rats that received an injection of vehicle before RSV inoculation.

SP (NK1) receptor mRNA in the lungs of rats that had been infected with RSV $30 \mathrm{~d}$ earlier was $43 \%$ higher than in controls that were kept pathogen-free, but this difference was not statistically significant $(p>0.05)$.

Enzyme-linked immunoassay revealed a large increase in SP concentration in the lungs of rats during and after infection with RSV. Five days postinoculation (Fig. 4, left columns), SP concentration in the lung tissues of RSV-infected rats was 3.4-fold higher than in pathogen-free controls $(p<0.001)$. Thirty days postinoculation (Fig. 4, right columns), this difference was still significant, although its magnitude had decreased to 2.6-fold $(p<0.05)$.

In the absence of nerve stimulation (Fig. 5, left columns), SP concentration measured in BAL samples obtained $30 \mathrm{~d}$ after inoculation was 1.4-fold higher in rats post-RSV infection than in controls that were kept pathogen-free $(p<0.01)$. After stimulation of sensory nerves with capsaicin (Fig. 5, right
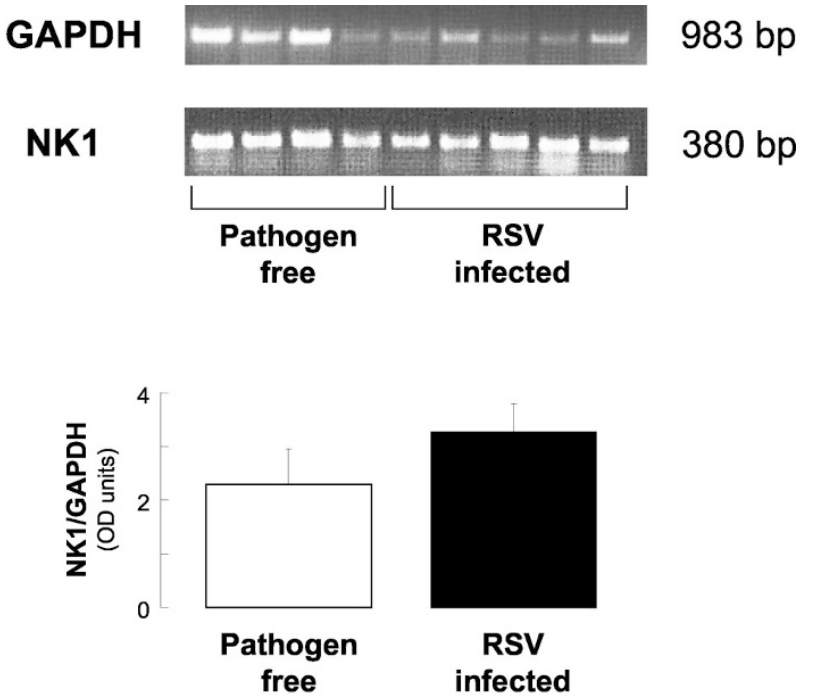

Figure 3. Amplification of SP (NK1) receptor mRNA from lung tissues of F-344 rats $30 \mathrm{~d}$ after endotracheal inoculation of RSV or virus-free medium. Total RNA was reverse-transcribed to cDNA, amplified by PCR using primers specific for GAPDH and for the SP (NK1) receptor, and analyzed by electrophoresis on an ethidium bromide-stained agarose gel. Densitometry analysis revealed a small increase in SP (NK1) receptor mRNA from the lungs of RSV-infected rats compared with pathogen-free controls, which was not statistically significant.

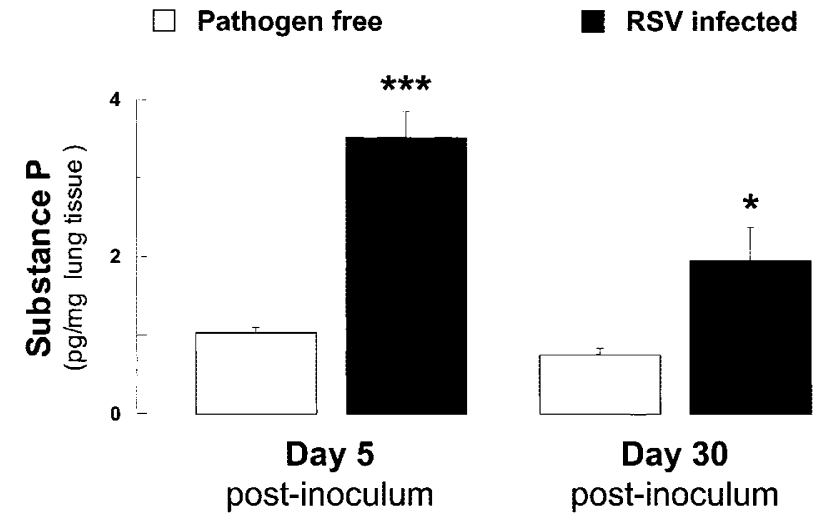

Figure 4. SP concentration in the lungs of rats during and after infection with RSV measured by enzyme-linked immunoassay. SP concentration in the lung tissues of RSV-infected rats was higher than in pathogen-free controls $5 \mathrm{~d}$ postinoculation, and this difference was still significant $30 \mathrm{~d}$ postinoculation; ${ }^{*} p<0.05 ;{ }^{* * *} p<0.001$, significantly different from pathogen-free controls.

columns), SP concentration in BAL increased significantly both in post-RSV rats $(p<0.001)$ and in controls $(p<0.001)$, but the concentration measured in previously infected rats was approximately twice that measured in pathogen-free controls that received an injection of the same dose of capsaicin $(p<$ $0.001)$.

\section{DISCUSSION}

The results of this study indicate that the potentiation of neurogenic-mediated inflammatory reactions caused by lower respiratory tract infection with RSV is still present after resolution of the infection, as manifested by the exaggerated increase of microvascular permeability in response to sensory 
$\square$ Pathogen-free

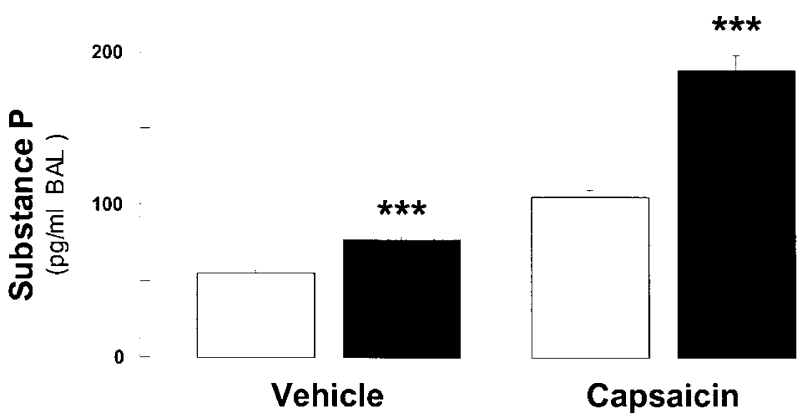

Figure 5. SP concentration in BAL samples obtained $30 \mathrm{~d}$ after RSV inoculation. After stimulation of sensory nerves with capsaicin, SP concentration in BAL from previously infected rats was approximately twice that measured in pathogen-free controls that received an injection of the same dose of capsaicin; $* * * p<0.001$, significantly different from pathogen-free controls.

nerve stimulation observed $30 \mathrm{~d}$ after inoculation of the virus. This potentiation is not only qualitatively but also quantitatively similar to the response measured during the acute phase of the infection $(4,8)$. The surprising observation that the vascular response to exogenous SP is no longer potentiated $30 \mathrm{~d}$ after the infection, combined with the lack of significant difference in expression of the high-affinity SP receptor, indicates that the mechanism of postinfectious potentiation of neurogenic inflammation operates predominantly at the presynaptic level with minor involvement of the postsynaptic component active during the acute phase of the infection (4).

The presence of RSV in the lower respiratory tract $5 \mathrm{~d}$ after inoculation was confirmed by titration of replicating virus and by immunohistochemical localization of specific viral antigens in the bronchiolar epithelium. However, viral antigens were not detected $30 \mathrm{~d}$ after RSV inoculation, despite that a strong potentiation of neurogenic-mediated inflammation was still present. In addition, $30 \mathrm{~d}$ after inoculation, neither replicating virus nor viral genome sequences could be detected in the lung tissues using the standard plaque assay and RT-PCR, respectively. Finally, the cellular infiltration in response to the acute infection had resolved by $30 \mathrm{~d}$, and the lung tissue architecture seemed completely normal. These observations suggest that the influence of RSV on the regulatory elements of the neurogenic inflammatory pathway persists after the virus is cleared from the respiratory tract.

This study also shows that the time course of RSV infection in F-344 rats resembles the typical course in humans, in contrast to other animal models that are unable to clear this virus even after several months (18). Thus, our model is particularly useful to study the long-term physiologic abnormalities after a mild and transient lower respiratory tract infection with RSV.

Post-RSV potentiation of neurogenic-mediated inflammation in the respiratory tract was prevented by passive prophylaxis with a MAb against the RSV fusion protein, which prevents spreading of the infection to the lower respiratory tract. No inhibition of neurogenic inflammation was found when palivizumab was given after inoculation of the virus. These findings suggest that protection against early RSV lower respiratory tract infection by passive prophylaxis may also protect against the chronic sequelae of this infection and particularly reduce the incidence of postbronchiolitis childhood asthma $(19,20)$. This hypothesis is supported by a recent report based on the retrospective analysis of children protected with polyclonal RSV immune globulin (21) and is also being tested in an ongoing clinical trial involving the more potent $\mathrm{MAb}$ palivizumab (22).

An interesting incidental finding was that the difference in weight between RSV-infected rats and pathogen-free controls noted during the acute phase of the infection (8) was still significant $30 \mathrm{~d}$ after the infection. This suggests that RSV may have persistent extrapulmonary sequelae, possibly related to the release of locally generated inflammatory mediators into the systemic circulation. Palivizumab had a partial protective effect against post-RSV weight loss, although this protective effect was not found at $5 \mathrm{~d}$ postinoculation (8), suggesting that mediators released during infection of the upper airways (which is not inhibited by palivizumab) promote weight loss during the acute phase, whereas other mechanisms activated by infection of the lower respiratory tract contribute to a persistent deficit. Our findings also suggest that RSV infection, particularly with severe lower respiratory tract involvement, may affect child growth more profoundly than currently thought, and this may warrant further clinical investigation.

Mechanisms of post-RSV potentiation of neurogenic inflammation. Previous work has shown that the potentiation of neurogenic-mediated inflammation seen in the respiratory tract during the acute phase of RSV infection is primarily postsynaptic (4) and derives from up-regulation of the high-affinity SP receptor (NK1 subtype) $(4,8)$. Down-regulation of the regulatory enzyme neutral endopeptidase seen in airways infected with other common viral pathogens (e.g. parainfluenza, influenza) (23) does not occur with RSV (4); therefore, the effects of this virus cannot be explained with decreased catabolism of SP released from sensory nerve fibers.

In the present study, we show that although the expression of this receptor remains slightly increased after resolution of the acute infection, it is unlikely to be the primary mechanism responsible for the postinfection changes in neurogenic inflammation. Rather, the persistence of abnormal inflammatory responses seems to depend on a presynaptic mechanism and specifically derives from structural and/or functional remodeling of the sensory innervation serving the airways, which results in a larger SP content (as a result of increased peptide synthesis and/or increased number of peptide-containing nerve fibers) and the release of larger amounts of SP after nociceptive nerve stimulation. The small SP increase in the BAL of unstimulated rats postinfection may reflect increased expression of this peptide in nonneural cells (e.g. macrophages) and/or be the effect of sensory nerves stimulation by the BAL itself. Increased expression of SP has also been shown in nonnociceptive vagal afferent neurons of guinea pigs infected with parainfluenza virus (24). Thus, the experimental evidence supporting a presynaptic mechanism for the postviral potentiation of neurogenic inflammation is 3-fold: 1) lack of significant vascular response at $30 \mathrm{~d}$ postinoculation of RSV to the same dose of SP that caused large exudation $5 \mathrm{~d}$ postinoculation, 2) lack of persistent elevation of mRNA encoding the SP 
(NK1) receptor $30 \mathrm{~d}$ postinoculation, and 3) increased content and increased release of SP from capsaicin-sensitive sensory nerves in lung tissues $30 \mathrm{~d}$ postinoculation.

The finding of increased SP levels at $30 \mathrm{~d}$ is important because a previous study using a murine model of RSV infection found increased levels of SP in the BAL only during the acute phase of the infection, i.e. peaking at $4 \mathrm{~d}$ after primary infection, but returning to baseline by day 6 (25). However, this study did not analyze SP expression in lung tissues, measure SP expression at later time points, or explore the release of SP from C-type nerve fibers. Our study shows that $\mathrm{SP}$ expression is increased in lung tissues both during and after the infection and that large amounts of this peptide are released upon sensory nerves stimulation even after resolution of the infection. Of course, some of the differences between our data and the data obtained in the murine model may also derive from the different species involved.

The changes in sensory innervation reported in this article may be linked to the potent up-regulation of the expression of nerve growth factor (NGF) and its high-affinity (trkA) and low-affinity (p75) receptors recently demonstrated in RSVinfected airways (26). NGF (27) is a key regulatory element of neuronal development and responsiveness (28), controls the expression of genes encoding the precursors of SP and other peptide neurotransmitters in sensory neurons (29), and amplifies the release of neurotransmitters from nerve terminals via increased expression and function of vanilloid receptors (30). In addition, NGF acutely up-regulates SP (NK1) receptor mRNA expression, and selective inhibition of this neurotrophin inhibits RSV-induced up-regulation of SP (NK1) receptor mRNA expression as well as the neurogenic inflammatory changes in virus-infected airways (26). On the basis of the results of the present study, we propose that RSV, via the overexpression of NGF, activates a dual mechanism to potentiate neurogenic inflammatory responses, with a short-term predominantly postsynaptic component deriving from upregulation of the SP receptor and a longer-term predominantly presynaptic component deriving from remodeling of sensory innervation. This sequential activation/deactivation of different mechanisms may result from counterregulatory events that affect differentially the pre- and postsynaptic effects of NGF. However, additional studies are necessary to verify this hypothesis and complete the exploration of this complex system.

\section{CONCLUSIONS}

This study shows that RSV causes a persistent increase in the susceptibility of the respiratory tract to the proinflammatory effects of sensory nerves, which is still present after the acute phase of the infection resolves as manifested by the exaggerated increase in vascular permeability observed $30 \mathrm{~d}$ after inoculation of the virus. The marked increase in the expression of SP (NK1) receptor mRNA found in the lungs of acutely infected rats declines after resolution of the infection, suggesting that a different mechanism is involved in the chronic phase of post-RSV airway inflammation. On the basis of the data presented in this study, we propose that the sensory innervation in the airways undergoes remodeling after an acute RSV infection, resulting in increased supply and/or responsiveness of SP-releasing nerves. Our data also show that preventing the spreading of the infection to the lower respiratory tract by passive prophylaxis may inhibit postinfectious changes in the neurogenic inflammatory pathway. Although multiple neural and immunoinflammatory mechanisms are involved in the complex defense system protecting the respiratory tract against viruses, the potentiation of neurogenic-mediated inflammation in response to RSV infection may represent an important component of the pulmonary inflammatory reaction to this virus observed in humans. If so, then pharmacologic inhibition of this inflammatory pathway via modulation of neuropeptide receptors expression or specific prophylaxis against the virus may minimize the acute response to RSV and perhaps influence the development of airway hyperresponsiveness observed in a large proportion of children with a history of RSV bronchiolitis.

Acknowledgments. The authors thank Drs. Xiaobo Jiang, Chengping $\mathrm{Hu}$, and Mian $\mathrm{Xu}$ for valuable technical assistance. We also thank Dr. M. Aatif Khan for helping with the RT-PCR detection of RSV and Dr. Maria Rodriguez for helping with the histopathology.

\section{REFERENCES}

1. Hall CB 2001 Respiratory syncytial virus and parainfluenza virus. N Engl J Med 344:1917-1928

2. Shay DK, Holman RC, Newman RD, Liu LL, Stout JW, Anderson LJ 1999 Bronchiolitis-associated hospitalizations among US children, 1980-1996. JAMA 282:1440-1446

3. Piedimonte G 2002 Origins of reactive airways disease in early life: do viral infections play a role? Acta Paediatr 91(suppl 437):6-11

4. Piedimonte G, Rodriguez MM, King KA, McLean S, Jiang X 1999 Respiratory syncytial virus upregulates expression of the substance $\mathrm{P}$ receptor in rat lungs. Am J Physiol 277:L831-L840

5. Piedimonte G, King KA, Holmgren NL, Bertrand PJ, Rodriguez MM, Hirsch RL 2000 A humanized monoclonal antibody against respiratory syncytial virus (palivizumab) inhibits RSV-induced neurogenic-mediated inflammation in rat airways. Pediatr Res 47:351-356

6. Piedimonte G, Nadel JA, Umeno E, McDonald DM 1990 Sendai virus infection potentiates neurogenic inflammation in the rat trachea. J Appl Physiol 68:754-760

7. Piedimonte G, McDonald DM, Nadel JA 1990 Glucocorticoids inhibit neurogenic plasma extravasation and prevent virus-potentiated extravasation in the rat trachea. J Clin Invest 86:1409-1415

8. King KA, Hu C, Rodriguez MM, Romaguera R, Jiang X, Piedimonte G 2001 Exaggerated neurogenic inflammation and substance $\mathrm{P}$ receptor upregulation in RSV-infected weanling rats. Am J Respir Cell Mol Biol 24:101-107

9. Routledge EG, McQuillin J, Samson AC, Toms GL 1985 The development of monoclonal antibodies to respiratory syncytial virus and their use in diagnosis by indirect immunofluorescence. J Med Virol 15:305-320

10. Dakhama A, Chan NG, Ahmad HY, Bramley AM, Vitalis TZ, Hegele RG 1998 Usefulness of bronchoalveolar lavage for diagnosis of acute and persistent respiratory syncytial virus lung infections in guinea pigs. Pediatr Pulmonol 26:396-404

11. Saria A, Lundberg JM, Skofitsch G, Lembeck F 1983 Vascular protein leakage in various tissues induced by substance $P$, capsaicin, bradykinin, serotonin, histamine, and by antigen challenge. Naunyn Schmiedebergs Arch Pharmacol 324:212-218

12. Holzer P 1991 Capsaicin: cellular targets, mechanisms of action, and selectivity for thin sensory neurons. Pharmacol Rev 43:143-201

13. Yokota Y, Sasai Y, Tanaka K, Fujiwara T, Tsuchida K, Shigemoto R, Kakizuka A, Ohkubo H, Nakanishi S 1989 Molecular characterization of a functional cDNA for rat substance P receptor. J Biol Chem 264:17649-17652

14. Siber GR, Leombruno D, Leszczynski J, McIver J, Bodkin D, Gonin R, Thompson CM, Walsh EE, Piedra PA, Hemming VG, Prince GA 1994 Comparison of antibody concentrations and protective activity of respiratory syncytial virus immune globulin and conventional immune globulin. J Infect Dis 169:1368-1373

15. Johnson S, Oliver C, Prince GA, Hemming VG, Pfarr DS, Wang SC, Dormitzer M, O'Grady J, Koenig S, Tamura JK, Woods R, Bansal G, Couchenour D, Tsao E, Hall WC, Young JF 1997 Development of a humanized monoclonal antibody (MEDI-493) with potent in vitro and in vivo activity against respiratory syncytial virus (RSV). J Infect Dis 176:1215-1224

16. Zar JH 1984 Two-factor analysis of variance. In: Biostatistical Analysis. PrenticeHall, Englewood Cliffs, NJ, pp 206-235

17. Wallenstein S, Zucker CL, Fleiss JL 1980 Some statistical methods useful in circulation research. Circ Res 47:1-9

18. Dakhama A, Vitalis TZ, Hegele RG 1997 Persistence of respiratory syncytial virus (RSV) infection and development of RSV-specific IgG1 response in a guinea-pig model of acute bronchiolitis. Eur Respir J 10:20-26 
19. Sigurs N, Bjarnason R, Sigurbergsson F, Kjellman B 2000 Respiratory syncytial virus bronchiolitis in infancy is an important risk factor for asthma and allergy at age 7 . Am J Respir Cell Mol Biol 161:1501-1507

20. Stein RT, Sherril D, Morgan WJ, Holberg CJ, Halonen M, Taussig LM, Wright AL, Martinez FD 1999 Respiratory syncytial virus in early life and risk of wheeze and allergy by age 13 years. Lancet 354:541-545

21. Wenzel SE, Gibbs RL, Lehr MV, Simoes EA 2002 Respiratory outcomes in high-risk children 7 to 10 years after prophylaxis with respiratory syncytial virus immune globulin. Am J Med 112:627-633

22. Piedimonte G, Simoes EA 2002 Respiratory syncytial virus and subsequent asthma: one step closer to unravelling the Gordian knot? Eur Respir J 20:515-517

23. Piedimonte G, Nadel JA 1996 Role of peptidases in airway defense mechanisms. In: Chretien J, Dusser D (eds) Airways and Environment: From Injury to Repair. Marcel Dekker, New York, pp 123-153

24. Carr MJ, Hunter DD, Jacoby DB, Undem BJ 2002 Expression of tachykinins in nonnociceptive vagal afferent neurons during respiratory viral infection in guinea pigs. Am J Respir Crit Care Med 165:1071-1075
25. Tripp RA, Moore D, Winter J, Anderson LJ 2000 Respiratory syncytial virus infection and $\mathrm{G}$ and/or $\mathrm{SH}$ protein expression contribute to substance $\mathrm{P}$, which mediates inflammation and enhanced pulmonary disease in BALB/c mice. J Virol $74: 1614-1622$

26. Hu C, Wedde-Beer K, Auais A, Rodriguez MM, Piedimonte G 2002 Nerve growth factor and nerve growth factor receptors in respiratory syncytial virus-infected lungs. Am J Physiol 283:L494-L502

27. Levi-Montalcini R 1987 The nerve growth factor 35 years later. Science 237:11541162

28. Kernie SG, Parada LF 2000 The molecular basis for understanding neurotrophins and their relevance to neurologic disease. Arch Neurol 57:654-657

29. Lindsay RM, Harmar AJ 1989 Nerve growth factor regulates expression of neuropeptide genes in adult sensory neurons. Nature 337:362-364

30. Ji RR, Samad TA, Jin SX, Schmoll R, Woolf CJ 2002 p38 MAPK activation by NGF in primary sensory neurons after inflammation increases TRPV1 levels and maintains heat hyperalgesia. Neuron 36:57-68 